\title{
Proteinograma sérico e do líquido peritoneal de equinos submetidos à orquiectomia
}

\author{
Serum and peritoneal protein profile of horses subjected to orchiectomy
}

\section{Paula Alessandra Di Filippo ${ }^{I^{*}}$ Fernando Ramalho Gomes $^{\mathrm{I}}$ Laiza da Silva Mascarenhas ${ }^{\mathrm{I}}$ Adriana Jardim de Almeida ${ }^{I}$ Ana Bárbara Freitas Rodrigues ${ }^{I}$}

\section{RESUMO}

Avaliou-se a resposta de fase aguda através da determinação da concentração das proteínas de fase aguda (PFAs) no soro sanguíneo e no líquido peritoneal de dez equinos submetidos à orquiectomia. Foram colhidas amostras de sangue e líquido peritoneal antes do procedimento de orquiectomia (TO) e diariamente, até o sexto dia (T1-T6) pós-operatório. As PFAs foram separadas por eletroforese em gel de poliacrilamida contendo SDS-PAGE, e suas concentrações determinadas por densitometria computadorizada. Foram identificadas no soro e no líquido peritoneal, no pré e pós-operatório, as proteínas ceruloplasmina, transferrina, albumina, haptoglobina e alglicoproteína ácida. No pós-operatório, verificaram-se alterações nas concentrações séricas e peritoneais das PFAs, as quais foram associadas à resposta inflamatória desencadeada pelo trauma cirúrgico. A orquiectomia desencadeia reação inflamatória em equinos e o proteinograma pode ser utilizado para diagnosticar e monitorar complicações pós-operatórias.

Palavras-chave: castração, resposta de fase aguda, eletroforese, cavalos.

\section{ABSTRACT}

The acute phase response was evaluated by determining the concentration of acute phase proteins (APP) in blood serum and peritoneal fluid in ten equines submitted to orchiectomy blood and peritoneal fluid samples were collected before the orchiectomy procedure (TO) and daily until the sixth postoperative day (T1-T6). The APPs were separated by electrophoresis on polyacrylamide gel containing SDS - PAGE and their concentrations were determined by computerized densitometry. There were identified in serum and peritoneal fluid, during pre and postoperative period, the acute phase proteins: ceruloplasmin, transferrin, albumin, haptoglobin and al-acid glycoprotein. Postoperatively, there were changes in serum and peritoneal APPs, which were associated with the inflammatory response induced by surgical trauma. The orchiectomy triggers inflammatory reaction in equines and the proteinogram can be used to diagnose and monitor the postoperative complications.

Key words: castration, acute phase response, electrophoresis, horses.

\section{INTRODUÇÃO}

A orquiectomia, frequentemente realizada em equinos, visa a eliminar o comportamento de garanhão dos animais não destinadosà reprodução, facilitando o manejo. Possui ainda indicação em neoplasias e traumas testiculares, orquites, torção do cordão espermático, hidrocele, varicocele e hérnias inguinais (MOLL et al., 1995).

Complicações advindas da orquiectomia podem ocorrer imediatamente, dias ou meses após cirurgia e, apesar de existirem poucos estudos sobre a incidência de complicações associadas à técnica, sabe-se que o potencial existe, principalmente ao considerar as condições em que o procedimento é realizado e os componentes anatômicos e individuais envolvidos. Cavalos de raças excitáveis e que apresentem doenças concomitantes, cordão espermático mais espesso, anel inguinal grande, histórico de hérnia escrotal, dermatites e/ou feridas na pele escrotal são mais susceptíveis a desenvolverem complicações. Procedimento cirúrgico realizado a campo, antissepsia duvidosa, falha no uso do emasculador ou na ligadura do cordão vascular espermático, material de sutura e/ou de cirurgia impróprios, uso da técnica aberta, cicatrização por

\footnotetext{
'Centro de Ciências e Tecnologias Agropecuárias (CCTA), Universidade Estadual do Norte Fluminense "Darcy Ribeiro" (UENF), Avenida Alberto Lamego, n 2000, 28013-602, Campos dos Goytacazes, RJ, Brasil. E-mail: pdf@ uenf.br. *Autor para correspondência. 
segunda intenção, inabilidade cirúrgica, trauma tecidual excessivo e pós-operatório inadequado, com presença de moscas ou uso de duchas também são fatores desencadeantes de complicações (MOLL et al., 1995; MAY \& MOLL, 2002).

Hemorragia (DI FILIPPO et al., 2012), edema excessivo, peritonite, eventração, hidrocele, hipertermia, claudicação (MOLL et al., 1995), comportamento de garanhão persistente, trauma peniano iatrogênico, hematoma (MAY \& MOLL, 2002), tétano, diarreia e morte já foram descritas em equinos submetidos à orquiectomia. Porém as complicações mais frequentes consistem na inflamação excessiva e na infecção (JACOBSEN et al., 2005).

O monitoramento da resposta inflamatória em equinos pode ser um desafio clínico, pois os sinais clássicos da inflamação nem sempre se manifestam clinicamente. Dessa forma, a busca porparâmetros indicativos da presença deinflamação nestes animais tem sido constante e intensa. Nas duas últimas décadas, o interesse centrou-se sobre o potencial das proteínas de fase aguda (PFAs), como indicadores da presença, grau e, naturalmente, do tempo de inflamação, uma vez que estas proteínas são liberadas em grandes quantidades para a corrente sanguínea em resposta à infecção e lesão de tecidos. Componentes não específicos do sistema imune, as PFAs estão envolvidas na restauração da homeostase e no combate ao crescimento microbiano, antecedendo o desenvolvimento da imunidade adquiridafrente a um desafio (MURATA, 2004; JACOBSEN \& ANDERSEN, 2007).

Nesse sentido, objetivou-se avaliar a resposta inflamatória, através da determinação dos valores de PFAs, no sangue e no líquido peritoneal de equinos submetidos à orquiectomia, a fim de diagnosticar e monitorar complicações pósoperatórias.

\section{MATERIAL E MÉTODOS}

Utilizaram-se 10 equinos hígidos não castrados, de diferentes raças, com média de idade de 4,2 $\pm 1,2$ anos, escore corporal de três a quatro e peso corporal médio de $298,7 \pm 31,7 \mathrm{~kg}$. Para o procedimento cirúrgico de orquiectomia, após jejum hídrico e alimentar de seis e 12 horas, respectivamente, os animais receberam cloridrato de xilazina ${ }^{a}$ a $10 \%$ na dose de $0,5 \mathrm{mg} \mathrm{kg}^{-1}$, pela via intravenosa (IV). Cinco minutos depois, procedeu-se à infusão IV rápida da solução a $10 \%$ de éter gliceril guaicol ${ }^{\mathrm{b}}$ e, após decúbito, administrou-se $2 \mathrm{mg} \mathrm{kg}^{-1}$, IV, de cetamina ${ }^{\mathrm{c}}$.
Para a anestesia local (intratesticular e subcutâneo), utilizou-se cloridrato de lidocaína ${ }^{\mathrm{d}}$ sem vasoconstritor (15-20ml em cada testículo).

Após higienização do escroto e região inguinal com água e detergente neutro, seguiu-se a antissepsia com solução de polivinilpirrolidona-iodo tópica a 1\% (PVPI 1\%) e álcool iodado. Duas incisões de aproximadamente $8-10 \mathrm{~cm}$ de comprimento foram realizadas na pele escrotal, paralelas à rafe mediana e a aproximadamente $2 \mathrm{~cm}$ desta, atingindo a fáscia escrotal e as túnicas dartos e parietal para exposição do testículo. Após exposição, realizou-se a penetração do mesórquio e, na sequência, seccionou-se o ligamento da cauda do epidídimo. Isso foi feito para liberar a túnica parietal e músculo cremaster e expor o cordão vascular espermático e ducto deferente, que posteriormente foram ligados utilizando-se fio poligalactina $910^{\mathrm{e}} \mathrm{com}$ tranfixação, ligadura e sobreligadura das estruturas deste.

No pós-operatório, foi instituída terapia antimicrobiana com penicilina benzatina ${ }^{\mathrm{f}}$, na dose de

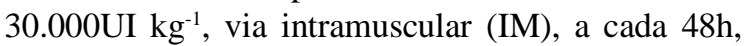
perfazendo três aplicações. Como analgésico e antiinflamatório, administrou-se flunixin meglumine ${ }^{\mathrm{g}}$, na dose de $1,1 \mathrm{mg} \mathrm{kg}^{-1}$, IV, a cada $24 \mathrm{~h}$, durante três dias. Foi realizado curativo da ferida cirúrgica com PVPI a $1 \%$, duas vezes ao dia e spray de sulfadiazina prata ${ }^{\mathrm{h}}$ até a cicatrização da ferida.

Para colheita das amostras de sangue, mediante punção da jugular, utilizaram-se agulhas $25 \times 8$, seringas plásticas descartáveis e frascos estéreis sem anticoagulante (EDTA). O líquido peritoneal foi obtido através da paracentese abdominal com o auxílio de uma cânula mamária de $60 \mathrm{~mm}$ de comprimento. Após a colheita, as amostras de líquido peritoneal e as de sangue, foram centrifugadas a 2000rpm por cinco minutos e, após sinérese e dosagem das proteínas totais, as alíquotas remanescentes foram acondicionadas em tubos do tipo eppendorf, identificadas e armazenadas a $-20^{\circ} \mathrm{C}$ até o momento da análise eletroforética. As concentrações de proteínas totais séricas e peritoneais foram obtidas pelo método do Biureto, com o auxílio de um conjunto de reagentesi e leituras espectrofotométricas ${ }^{j}$.

Para o fracionamento eletroforético das frações proteicas do soro e do líquido peritoneal, procedeu-se à eletroforese em gel de poliacrilamida, contendo dodecil sulfato de sódio (SDS-PAGE). Os pesos moleculares e as concentrações das frações proteicas foram determinados por densitometria computadorizadak ${ }^{\mathrm{k}}$. Para o cálculo do peso molecular, foram utilizados marcadores ${ }^{1}$ de pesos moleculares de 200, 116, 97, 66, 55, 45, 36, 29, 24 e 20kDa, além das 
proteínas purificadas albumina, $\alpha 1$-antitripsina, haptoglobina, ceruloplasmina, transferrina e imunoglobulina $G(\operatorname{IgG})$. Para cada equino, as amostras de sangue e de líquido peritoneal foram colhidas antes do procedimento cirúrgico (T0), $24,48,72,96,120$ e 144 horas após orquiectomia (T1-T6).

A análise estatística dos dados foi estabelecida por meio do teste de Tukey, fixando-se a variância em $\mathrm{P}<0,05$ para comparação das médias, através do programa estatístico SAS.

\section{RESULTADOS E DISCUSSÃO}

Os resultados obtidos para os constituintes do proteinograma sérico e peritoneal, com as respectivas médias, desvios-padrão e significância estatística estão expressos nas tabelas 1 e 2 .

Houve aumento $(\mathrm{P}<0,05)$ na concentração sérica de haptoglobina e de $\alpha 1$ - glicoproteína ácida nos T4 e T5 (Tabela 1), que correspondem ao quarto e quinto dia pós-operatório, respectivamente. No líquido peritoneal, verificou-se aumento nos valores de haptoglobina nos momentos T1 a T6 e de $\alpha 1$ glicoproteína ácida nos T5 e T6. Acrescido a estes resultados, observou-se diminuição $(\mathrm{P}<0,05)$ nos valores de transferrina (T1 a T6) e de albumina (T3 a T6) no líquido peritoneal dos animais ensaiados (Tabela 2). As alterações deveram-se ao trauma cirúrgico, inerente ao procedimento de orquiectomia, visto que o pós-operatório transcorreu sem complicações. Resultados semelhantes foram observados por POLLOCK et al. (2005), JACOBSEN et al. (2005) e por BUSK et al. (2010), no pósoperatório de equinos submetidos à orquiectomia. De acordo com BUSK et al. (2010), alterações nas concentrações de proteínas de fase aguda após procedimentos de orquiectomia são esperadas, são esperadas, visto que a técnica acarreta, aos tecidos envolvidos, um trauma cirúrgico muito severo. O conhecimento da resposta de fase aguda, frente a um pós-operatório sem intercorrências pode permitir o uso destes e de outros marcadores inflamatórios no diagnóstico precoce de complicações. Ou seja, um desvio no padrão de normalidade pode indicar que complicações, tais como inflamação excessiva e/ou infecção, possam ter ocorrido. Frente a este contexto, ensaio realizado por JACOBSEN et al. (2005) revelou que somente os animais que desenvolveram processo inflamatório exacerbado e/ou infecção após orquiectomia apresentaram níveis permanentemente elevados de amiloide A, principal marcador inflamatório em equinos. Nos animais que não apresentaram complicações pósoperatórias, os valores retornaram a normalidade no oitavo dia após orquiectomia. No ensaio em tela, as alterações séricas retornaram aos valores basais no decorrer dos seis dias de observação. Entretanto, no líquido peritoneal, os momentos abrangidos foram insuficientes para a avaliação da cinética das PFAs mensuradas.

A resposta fisiológica ao trauma cirúrgico é um evento complexo, envolvendo e promovendo a interação entre numerosos mediadores inflamatórios, hormonais, metabólicos e imunológicos, cujo objetivo final é adaptar o organismo aos tecidos

Tabela 1 - Médias e desvios-padrão dos teores séricos de proteína total, transferrina, albumina, ceruloplasmina, haptoglobina e $\alpha$ 1glicoproteína ácida de equinos hígidos e submetidos à orquiectomia.

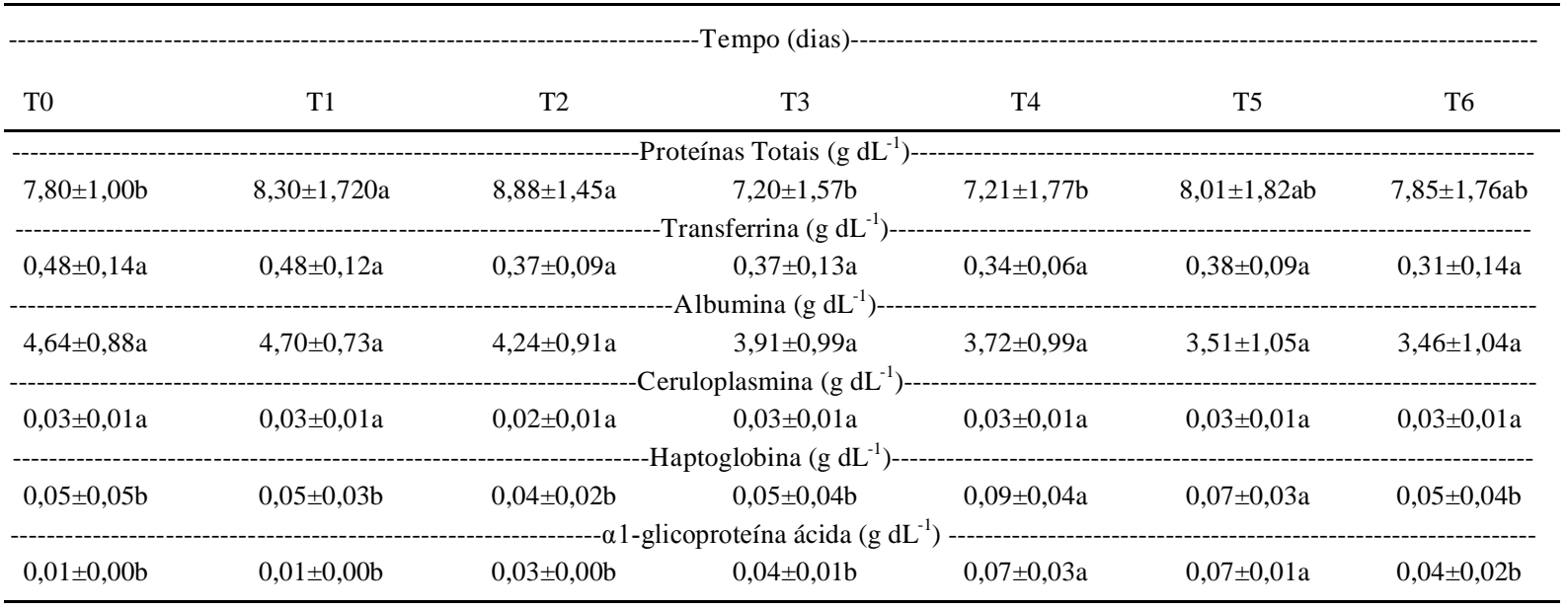

T0: pré-operatório; T1-T6: dias de pós-operatório.

Letras minúsculas distintas indicam diferença significativa entre tempos pelo Teste Tukey $(\mathrm{P}<0,05)$.

Ciência Rural, v.44, n.12, dez, 2014. 
Tabela 2 - Médias e desvios-padrão dos teores de proteína total, transferrina, albumina, ceruloplasmina, haptoglobina e $\alpha$ 1-glicoproteína ácida no líquido peritoneal de equinos hígidos e submetidos à orquiectomia.

\begin{tabular}{|c|c|c|c|c|c|c|}
\hline T0 & $\mathrm{T} 1$ & $\mathrm{~T} 2$ & T3 & T4 & T5 & T6 \\
\hline \multicolumn{7}{|c|}{ - } \\
\hline $1,71 \pm 0,33 b$ & $2,68 \pm 0,79 a$ & $2,70 \pm 1,63 a$ & $2,83 \pm 0,29 a$ & $2,91 \pm 0,27 \mathrm{a}$ & $2,73 \pm 0,32 \mathrm{a}$ & $2,43 \pm 0,42 a b$ \\
\hline $1,90 \pm 1,30 a$ & $1,40 \pm 1,30 \mathrm{~b}$ & $1,10 \pm 1,00 \mathrm{~b}$ & $\begin{array}{l}\text { sferrina }(\mathrm{g} \text { dI } \\
1,30 \pm 1,10 \mathrm{~b}\end{array}$ & $0,90 \pm 1,00 \mathrm{~b}$ & $1,30 \pm 1,20 \mathrm{~b}$ & $1,20 \pm 1,10 b$ \\
\hline $0,55 \pm 0,33 a$ & $0,55 \pm 0,30 \mathrm{a}$ & $0,39 \pm 0,30 \mathrm{a}$ & $0,26 \pm 0,12 b$ & $0,32 \pm 0,10 \mathrm{~b}$ & $0,35 \pm 0,20 b$ & $0,16 \pm 0,17 b$ \\
\hline $0,10 \pm 0,10 \mathrm{a}$ & $0,20 \pm 0,10 a$ & $0,20 \pm 0,20 \mathrm{a}$ & $0,30 \pm 0,10 \mathrm{a}$ & $0,30 \pm 0,20 \mathrm{a}$ & $0,20 \pm 0,06 a$ & $0,20 \pm 0,05 a$ \\
\hline $0,30 \pm 0,30 \mathrm{~b}$ & $0,60 \pm 0,04 a$ & $0,90 \pm 0,20 \mathrm{a}$ & $\begin{array}{c}\text { oglobina }(\mathrm{g} \mathrm{d} \\
1,30 \pm 0,90 \mathrm{a}\end{array}$ & $2,20 \pm 2,10 \mathrm{a}$ & $2,90 \pm 1,00 \mathrm{ba}$ & $4,40 \pm 2,50 \mathrm{a}$ \\
\hline $0,10 \pm 0,08 b$ & $0,20 \pm 0,30 \mathrm{~b}$ & $0,20 \pm 0,10 b$ & $\begin{array}{l}\text { oteina acida } \\
0,30 \pm 0,30 \mathrm{~b}\end{array}$ & $0,30 \pm 0,20 \mathrm{~b}$ & $0,80 \pm 0,60 \mathrm{a}$ & $0,50 \pm 0,50 \mathrm{a}$ \\
\hline
\end{tabular}

T0: pré-operatório; T1-T6: dias de pós-operatório.

Letras minúsculas distintas indicam diferença significativa entre tempos pelo Teste Tukey $(\mathrm{P}<0,05)$.

traumatizados e auxiliá-lo no processo de cura (GIANNOUDIS, 2003). Alterações nas concentrações de fibrinogênio, ferro e de amiloide A foram observados por JACOBSEN et al. (2009) no pós-operatório de equinos submetidos à artroscopia, laringoplastia e ovariectomia. Equinos submetidos à laparotomia exploratória também apresentaram resposta inflamatória associada ao trauma cirúrgico (SAQUETTI et al., 2008).

Marcadores inflamatórios, como as PFAs, refletem a intensidade do trauma cirúrgico e podem ser utilizados na avaliação de diferentes tipos de traumas e de técnicas cirúrgicas. Técnicas cirúrgicas menos invasivas, desencadeiam processo inflamatório pósoperatório de menor intensidade quando comparada a técnicas cirúrgicas abertas, como a orquiectomia. Corroborando tal assertiva, $341 \mathrm{mg} \mathrm{L}^{-1}$ foi o valor máximo de amiloide A observado por JACOBSEN et al. (2009), no pós-operatório de cindo equinos submetidos à laparotomia e ovariectomia. Neste mesmo estudo, animais submetidos à laringoplastia e ventriculectomia apresentaram valores máximos de $180 \mathrm{mg} \mathrm{L}^{-1}$. Com relação à orquiectomia, BUSK et al. (2010) demonstraram que esta técnica acarreta um trauma cirúrgico e, consequentemente, processo inflamatório ainda mais intenso. Valores de amiloide A iguais a $625 \mathrm{mg} \mathrm{dL}^{-1}$ foram observados no $3^{0} \mathrm{dia}$ após orquiectomia. Explicando, em parte, o fato de complicações serem tão frequentes após orquiectomia. Entretanto, segundo JACOBSEN et al. (2009) alguns fatores devem ser avaliados, pois podem influenciar os valores de PFAs obtidos. O ferro, o fibrinogênio e a haptoglobina podem sofrer variações, de acordo com a idade do animal. Neste ensaio, os animais apresentavam idades similares (3-5 anos). Ou seja, extremos de idade não foram incluídos.

O fator racial e o ritmo circadiano também poderiam interferir nos resultados. Entretanto, sabese que frente a um evento estressor, estes fatores não alteram a concentração de PFAs de maneira significativa. A ação antimicrobiana das penicilinas, o efeito anti-inflamatório dos anestésicos locais acrescidos, das ações do flunixin meglumine pode influenciar na intensidade da resposta inflamatória (BUSK et al., 2010). No ensaio em tela, todos os animais foram submetidos ao mesmo protocolo farmacológico. Estudos que não contemplem o uso de anti-inflamatórios e antibióticos no pós-operatório de equinos submetidos à orquiectomia são inexistentes, mesmo porque não refletiriam a realidade e iriam contra os princípios de ética e bem estar animal.

$\mathrm{O}$ uso da técnica aberta e posterior cicatrização por segunda intenção, como a realizada neste ensaio, também pode ter contribuído para os achados, já que o fechamento priomário apresenta, segundo MAY \& MOLL (2002), resolução mais rápida, menor chance de infecção e edema reduzido. Frente a estas considerações, BUSK et al. (2010) afirmaram que o uso do emasculador deflagra uma reação de fase aguda ainda mais intensa do que a técnica cirúrgica convencional (aberta e/ou fechada), sem o uso deste instrumental. Isso porque, com o emasculador, o cordão espermático é esmagado e não apenas incidido. Entretanto, ensaios que avaliem e/ou comparem a resposta de fase aguda frente a diferentes técnicas de orquiectomia são inexistentes. De acordo 
com JACOBSEN et al. (2009), a habilidade do cirurgião, assim como sua experiência profissional, poderia interferir nos resultados. Neste ensaio, todos os procedimentos de orquiectomia foram realizados pelo mesmo profissional experiente e os animais que, por diferentes motivos, necessitaram de maior manipulação do campo operatório e/ou apresentaram complicações transoperatórias e/ou pré-operatórias imediatas, foram excluído das análises.

Não foram observadas alterações nas concentrações séricas e peritoneais de ceruloplasmina (Cp), nos animais e tempos avaliados (Tabelas 1 e 2). Os resultados diferem dos obtidos por SAQUETTI et al. (2008) em equinos submetidos à obstrução experimental do cólon menor, para os quais os valores aumentados deveram-se ao reflexo da resposta inflamatória decorrente dos procedimentos cirúrgicos obstrutivos e da manipulação visceral, instituídos na consecução do modelo experimental. Acredita-se que tais diferenças residam no fato de que a concentração das PFAs é diretamente proporcional ao grau de lesão tecidual. Assim, espera-se que animais submetidos a traumas cirúrgicos mais invasivos, como o realizado por SAQUETTI et al. (2008), apresentem maior nível proteico. O uso da $\mathrm{Cp}$ para o diagnóstico de processos inflamatórios e infecciosos é menos comum do que outras PFAs. Entretanto, estudos demonstram que esta ferroxidase é eficaz para tal propósito em bovinos, aves e também equinos (MURATA et al., 2004). Por ser considerada uma PFA de fase intermediária ou tardia, acredita-seque a ausência de alterações verificadas neste ensaio deveu-se ao curto período de tempo avaliado. Corroborando tal assertiva, OKUMURA et al. (1991) observaram aumento nas concentrações de Cp a partir do sexto dia após orquiectomia. Valores máximos foram observados do sétimo ao décimo quarto dia pós-operatório e o retorno destes aos valores pré-operatórios, 28 dias após os procedimentos.

Observou-se, de forma geral, diminuição nos valores das PFAs negativas, albumina e transferrina, unicamente no líquido peritoneal dos animais ensaiados (Tabela 2). A redução da transferrina frente a processos inflamatórios representa um mecanismo de defesa do organismo, considerando que essa proteína sequestra íons férricos que podem servir como substrato para diversos microrganismos (MURATA et al., 2004). Resultados semelhantes foram observados por DI FILIPPO et al. (2011) em equinos com cólica de ocorrência natural e submetidos à laparotomia exploratória. Entretanto, NOGUEIRA et al. (2013) observaram aumento nos teores de transferrina e de albumina no líquido peritoneal de equinos submetidos à obstrução intestinal experimental. Tais achados residem no fato de que o comportamento de uma mesma PFA é variável, frente a diferentes estímulos e que nem todas as PFAs são igualmente sensíveis e rápidas quanto a sua resposta a um "fator desencadeante".

A ausência de alterações nos níveis séricos de transferrina e a detecção precoce desta e de outras variáveis no líquido peritoneal pode ter ocorrido devido à síntese extra-hepática das proteínas de fase aguda e ao desenvolvimento de uma possível peritonite subclínica (MOLL et al., 1995). Órgãos que se comunicam com o meio externo, tais como a glândula mamária, o sistema respiratório e o trato gastrintestinal são reconhecidamente produtores de PFAs (JACOBSEN et al., 2009). Para NOGUEIRA et al. (2013), o fracionamento eletroforético das proteínas contidas no líquido peritoneal foi mais sensível no diagnóstico de processos inflamatórios abdominais, quando comparado ao sérico. As células peritoneais produzem diversos tipos de citocinas, incluindo as IL-6, e procedimentos cirúrgicos, inflamatórios e/ ou infecciosos abdominais desencadeiam aumento substancial na concentração destas citocinas no líquido peritoneal, o que, possivelmente, afeta a magnitude da resposta de fase aguda pós-operatória (JACOBSEN et al., 2009).

Através do canal vaginal, a cavidade escrotal comunica-se diretamente com a cavidade abdominal e, por assim ser, uma peritonite secundária a orquiectomia pode se desenvolver (MOLL et al., 1995) e contribuir para os valores de PAFs mensurados no pós-operatório (BUSK et al., 2010). O desenvolvimento de um processo inflamatório abdominal acrescido da produção local de PFA explicariam as diferenças observadas com relação à intensidade e à precocidade das alterações verificadas neste ensaio, entre o proteinograma sérico e o peritoneal. Uma vez produzidas na cavidade abdominal, próximas aos tecidos traumatizados, as PAFs seriam secundariamente direcionadas para a corrente sanguínea e só então contribuiriam para a resposta de fase aguda sérica (BUSK et al., 2010). Creditando tais afirmações, valores médios máximos de leucócitos iguais a $15.558 \mu \mathrm{L}$ foram obtidos no líquido peritoneal dos animais no pós-operatório. A determinação dos níveis locais das proteínas de fase aguda, por fornecer informações sobre o status inflamatório/infeccioso de um órgão de particular interesse, aumenta a precisão na elaboração do diagnóstico. Ademais e à semelhança do mencionado anteriormente para a $\mathrm{Cp}$, a tranferrina é considerada uma proteína de fase aguda tardia. Valores séricos 
máximos são verificados cerca de 10 dias após estímulo, período este não abrangido no estudo.

Houve aumento na concentração de $\alpha 1$ glicoproteína ácida (AGP) no sangue (T4 e T5) e no líquido peritoneal (T5 e T6) dos animais avaliados. A AGP contribui para a manutenção da homeostase e é considerada um agente anti-inflamatório natural, inibindo a ativação de neutrófilos e estimulando a secreção de antagonistas do receptor IL-1 pelos macrófagos (MURATA et al., 2004). Assim sendo, diante de um trauma cirúrgico e o posterior desencadeamento de um processo inflamatório, era de se esperar aumento nos valores de AGP. Resultados semelhantes foram verificados por DI FILIPPO et al. (2011) em equinos com cólica. Entretanto, valores permanentemente aumentados foram observados unicamente nos animais que não sobreviveram à doença, permitindo a conclusão de que a AGP fornece informações sobre a gravidade do processo inflamatório/infeccioso.

Verificou-se aumento na concentração sérica (T4 e T5) e peritoneal (T1 a T6) de haptoglobina (Hp). Resultados semelhantes foram obtidos por KENT \& GOODALL (1991), os quais relataram a ocorrência de dois picos de elevação nos níveis séricos de $\mathrm{Hp}$ em equinos após orquiectomia, no terceiro e quinto dia pós-operatório. Avaliando-se os efeitos de diferentes procedimentos cirúrgicos, inclusive orquiectomia, na resposta de fase aguda em equinos, POLLOCK et al. (2005) observaram que os níveis séricos de Hp aumentaram lentamente após as cirurgias e assim permaneceram por até 72 horas. A Hp tem sido utilizada no diagnóstico e monitoramento de processos inflamatórios em equinos, no entanto, e segundo POLLOCK et al. (2005), suas concentrações respondem de forma relativamente lenta à inflamação e variam muito em animais hígidos.

\section{CONCLUSÃO}

A orquiectomia desencadeia reação inflamatória intensa, caracterizada por alterações nas concentrações séricas e peritoneais das proteínas de fase aguda. As alterações não se relacionam à ocorrência de complicações pós-operatórias e devem-se ao trauma cirúrgico.

O proteinograma do líquido peritoneal mostrou-se mais sensível que o sérico no diagnóstico e monitoramento de processos inflamatórios em equinos após orquiectomia. Amostras sequenciais permitem avaliar adequadamente aumentos e diminuições na atividade inflamatória.

\section{FONTES DE AQUISIÇÃO}

a - Sedomin ${ }^{\circledR} 10 \%$, Laboratórios König do Brasil Ltda, São Paulo, SP, Brasil.

b - Eter Gliceril Guaiacol - Henrifarma - São Paulo, SP, Brasil.

c - Cetamin 10\% - Syntec do Brasil Ltda. - São Paulo, SP, Brasil.

d - Lidovet 2\% - Bravet Ltda. - Rio de Janeiro, RJ, Brasil.

e - Vicryln ${ }^{0} 1$ - Johnson \& Johnson - São Paulo, SP, Brasil.

f - Pentabiótico Veterinário Reforçado - Fort Dodge Saúde Animal

- São Paulo, SP, Brasil.

g - Niglumine -Hertape Calier S.A. - Minas Gerais, MG, Brasil.

h - Bactrovet Prata AM - Laboratórios König S.A. -Argentina.

i - Labtest (Sistema de Diagnósticos Ltda. - Lagoa Santa, Brasil).

j - Labquest (CELM, modelo E-225-D).

k - Fotodyne, (Fotodyne Inc, Houston, TX, USA).

1 - Marcador (Sigma Marker 6.500 - 200.000).

\section{COMITÊ DE ÉTICA E BIOSSEGURANÇA}

Comissão de Ética no Uso de Animais (CEUA) da Universidade Estadual do Norte Fluminense (UENF), conforme protocolo $\mathrm{n}^{\circ} 137$.

\section{REFERÊNCIAS}

BUSK, P. et al. Administration of perioperative penicillin reduces postoperative serum amyloid A response in horses being castrated standing. Veterinary Surgery, v.39, p.638-643, 2010. Disponível em: <http://www.ncbi.nlm.nih.gov/pubmed/20459482>. Acesso em: 15 fev. 2014

DI FILIPPO, P.A. et al. Determinação de haptoglobina, ceruloplasmina, $\alpha 1$-glicoproteína ácida, transferrina e $\alpha 1$ antitripsina, em equinos com cólica. Ciência Rural, v.41, n.12, p.2108-2113, 2011. Disponível em: <http://www.scielo.br/scielo. php ?pid=S0103-84782011001200012\&script $=$ sci_arttext $>$. Acesso em: 25 nov. 2013.

DI FILIPPO, P.A. et al. Hemorragia associada à orquiectomia em equino: relato de caso. Revista Brasileira de Medicina Equina, v.7, n.40, p.20-23, 2012. Disponível em: <http://www. revistavetequina.com.br/>. Acesso em: 15 fev. 2014.

GIANNOUDIS, P.V. Current concepts of the inflamatory response after major trauma: an update. Injury, v.34, p.397404, 2003. Disponível em: <http://www.ncbi.nlm.nih.gov/ pubmed/12767787>. Acesso em: 15 fev.2014.

JACOBSEN, J. et al. Acute phase response to surgery of varying intensity in horses: a preliminary study. Veterinary Surgery, v.38, p.762-769, 2009. Disponível em: <http://www.ncbi.nlm.nih.gov/ pubmed/19674420>. Acesso em: 15 fev. 2014.

JACOBSEN, S. et al. Use of serum amyloid A and other acute phase reactants to monitor the inflammatory response after castration in horses: a field study. Equine Veterinary Journal, v.37, n.6, p.552-556, 2005. Disponível em: <http://onlinelibrary.wiley.com/ doi/10.2746/042516405775314853/pdf>. Acesso em: 26 nov. 2013.

JACOBSEN, S.; ANDERSEN, P.H. The acute phase protein serum amyloid A (SAA) as a marker of inflammation in horses. Equine Veterinary Education, v.19, n.1, p.38-46, 2007. Disponível em: <http://www.ncbi.nlm.nih.gov/pubmed/10918902>. Acesso em: 15 fev. 2014. 
KENT, J. E.; GOODALL, J. Assessment of an immunoturbidimetric method for measuring equine serum haptoglobin concentrations. Equine Veterinary Journal, v.23, n.1. p.59-66, 1991. Disponível em: <http://onlinelibrary.wiley.com/doi/10.1111/evj.1991.23.issue-1/ issuetoc>. Acesso em: 25 nov. 2013.

MAY, K.A.; MOLL, H.D. Recognition and management of equine castration complications. Compendium, v. 24, p.150162, 2002. Disponível em: <https://secure.vlsstore.com/Media/ PublicationsArticle/PV_24_02_150.pdf>. Acesso em: 15fev. 2014

MOLL, H. D. et al. A survey of equine castration complications. Journal of Equine Veterinary Science, v.15, n.12, p.522-526, 1995. Disponível em: <http://www.sciencedirect.com/science/ article/pii/S0737080607804217>. Acesso em: 25 nov. 2013.

MURATA. H. et al. Current research on acute phase proteins in veterinary diagnosis: an overview. Veterinary Journal, v.168, n.1, p.28-40, 2004. Disponível em: <www.elsevier.com/locate/ tvjl>. Acesso em: 15 fev. 2014.

NOGUEIRA, A.F.S. et al. Proteinograma sérico e do líquido peritoneal de equinos hígidos e daqueles submetidos à obstrução intestinal experimental. Ciência Rural, v.43, n.11, p.2018-2024, 2013. Disponível em: <http://www.scielo.br/pdf/cr/v43n11/ a31813cr2012-0890.pdf>. Acesso em: 25 nov. 2013.

OKUMURA, M. et al. Isolation, characterization, and quantitative analysis of ceruloplasmin from horses. American Journal of Veterinary Research, v.52, n.12, p.1979-1985, 1991. Disponível em: <http://www.ncbi.nlm.nih.gov/pubmed/1789511>. Acesso em: 05 maio, 2014.

POLLOCK, P.J, et al. Effects of surgery on the acute phase response in clinically normal and diseased horses. Veterinary Record, v.156, p.538-542, 2005. Disponível em: <http://www. ncbi.nlm.nih.gov/pubmed/15849343>. Acesso em: 15 fev. 2014.

SAQUETTI, C.H.C. et al. Perfil eletroforético do proteinograma sérico de equinos com obstrução experimental do cólon menor. Arquivo Brasileiro de Medicina Veterinária e Zootecnia, v.60, p.794-799, 2008. Disponível em: <http://www.scielo.br/ scielo.php?pid=S0102-09352008000400003\&script=sci_arttext $>$. Acesso em: 25 nov. 2013.

Ciência Rural, v.44, n.12, dez, 2014. 